\title{
Virulence and antigenic characteristics of a cultured Rickettsiales-like organism isolated from farmed Atlantic salmon Salmo salar in eastern Canada
}

\author{
Simon R. M. Jones ${ }^{1, *}$, R. J. Frederick Markham ${ }^{2}$, David B. Groman ${ }^{3}$, \\ R. Roland Cusack ${ }^{4}$ \\ 'Aqua Health Ltd, West Royalty Industrial Park, Charlottetown, Prince Edward Island C1E 1B0, Canada \\ ${ }^{2}$ Department of Pathology and Microbiology, Atlantic Veterinary College, University of Prince Edward Island, \\ 550 University Avenue, Charlottetown, Prince Edward Island C1A 4P3, Canada \\ ${ }^{3}$ Aquatic Diagnostic Services, Atlantic Veterinary College, University of Prince Edward Island, 550 University Avenue, \\ Charlottetown, Prince Edward Island C1A 4P3, Canada \\ ${ }^{4}$ Nova Scotia Department of Fisheries and Aquaculture, Veterinary Pathology Building, PO Box 550, Truro, \\ Nova Scotia B2N 5E3, Canada
}

\begin{abstract}
The present study describes culture, virulence and antigenic characteristics of a Rickettsiales-like organism (RLO) associated with mortality in farmed Atlantic salmon in eastem Canada. Clinical disease was reproduced in naive Atlantic salmon parr by intraperitoneal (IP) inoculation with kidney homogenate from naturally infected fish. Pure cultures of RLO were isolated into chınook salmon embryo (CHSE) cells from kidney of experimentally infected fish. The RLO caused cytopathic effect in cultured CHSE-214 typified by coalescing areas of swollen cells that eventually detached from the substrate. Bacteria in infected culture supernatants reacted with Piscirickettsia salmonis-specific polyclonal sera or monocional antibody (MAb) in an indirect fluorescent antibody test. IP inoculation with cultured RLO resulted in mortalıties of 100,62,22.5 and $0 \%$ in Atlantic salmon, coho salmon, rainbow trout and common carp, respectively. Cultured RLO were sensitive to chloramphenicol, flumequine, oxytetracycline and oxolinic acid and insensitive to gentamicin and amphotericin B. RLO antigens were compared with those of 3 strains of $P$. salmonis from Chilean salmon by SDS-PAGE and immunoblotting. A silverstaining band of about $12 \mathrm{kDa}$ was detected in proteinase $\mathrm{K}(\mathrm{PK})$ digests of all RLO strains, and a diffuse band of about $15 \mathrm{kDa}$ was observed in 2 Chilean strains only. No other silver-stained bands were visible in PK digests of any strain examined. The polyclonal serum recognized 9 proteln bands and multiple non-protein bands extending from less than $20 \mathrm{kDa}$ to greater than $95 \mathrm{kDa}$ in all isolates. The MAb reacted with an epitope in PK digests that occurred in all 4 strains on structures of widely ranging molecular masses, resulting in a ladder pattern similar to that obtained with polyclonal serum. Treatment of PK digests with periodic acid abolished reactivity with MAb and polyclonal serum. Co-elution of 2-keto-3-deoxyoctonate and MAb reactivity following size exclusion chromatography of solubilized $P$. salmonis suggested that the MAb recognized a lipopolysaccharide-associated epitope in all 4 RLO isolates. Cultural, virulence and antigenic similarities among the strains examined in the present study indicate that the eastern Canadian salmonid RLO should be considered a strain of $P$. salmonis.
\end{abstract}

KEY WORDS: Farmed salmon · Rickettsiales-like-organism · Cell culture · Antigens

\section{INTRODUCTION}

Intracellular parasites resembling those of the bacterial order Rickettsiales have been described from

•E-mail: simjones@upei.ca several species of marine and freshwater teleosts, crustaceans and molluscs (Fryer \& Lannan 1994). RLO (Rickettsiales-like organism) infections are usually non-pathogenic in aquatic animals, but there is increasing evidence that associates RLO with disease in farmed populations. Thus, clinical rickettsioses have 
been described among farmed salmon in Chile, Canada (British Columbia), Ireland, Scotland and Norway and in farmed tilapia in Taiwan (Fryer et al. 1990 , Brocklebank et al. 1992, Olsen et al. 1993, Rodger \& Drinnan 1993, Chern \& Chao 1994, Grant et al. 1996). Unlike the studies of the RLOs affecting mammals, few studies have reported on natural routes of transmission or pathogenic mechanisms of those affecting aquatic species (Almendras 1997a). Furthermore, most aquatic RLOs are genetically, biochemically and serologically undefined; thus, the relatedness of geographically or biologically distinct isolates remains unknown. A new genus was erected to accommodate an RLO, Piscirickettsia salmonis, affecting cultured salmon in Chile. The definition of this taxon was based on distinct nucleotide sequences in $16 \mathrm{~S}$ rRNA and on the ability of $P$. salmonis to infect salmonid fish (Fryer et al. 1992). The organism was subsequently shown, by sequence analysis of the $16 \mathrm{~S}$ rRNA gene, to be related to Francisella tularensis, Wolbachia persica and Coxiella burnetii (Mauel 1996). Using a similar analysis, the latter study also found evidence for relatedness among British Columbian and Norwegian salmonid RLOs and those from Chile. In addition, reactivity of anti- $P$. salmonis serum with some RLOs from European and British Columbian salmonids (Evelyn \& Kent 1992, Alday-Sanz et al. 1994) suggests at least 1 antigen is shared among these pathogens. A closer examination of genomic or ribosomal nucleotide sequences may be necessary to properly identify the various geographic isolates of RLOs from salmonid and non-salmonid aquatic hosts.

A recent occurrence of mortality among netpenreared Atlantic salmon Salmo salar in eastern Canada was shown to be associated with an RLO that was morphologically and serologically similar to Piscirickettsia salmonis (Cusack et al. 1997). The present report provides information on the culture, sensitivity to antibiotics and virulence of the eastern Canadian salmonid RLO and on the size and immunoreactivity of antigens associated with this isolate in an attempt to clarify its relationship to strains of $P$. salmonis obtained from Chile.

\section{MATERIALS AND METHODS}

Transmission of RLO by tissue inoculation. Fresh kidney from a farm-reared salmon, shown previously by histological and indirect fluorescent antibody (IFAT) examinations (Cusack et al. 1997) to be infected with the RLO, was aseptically macerated in sterile saline at $4^{\circ} \mathrm{C}$. Eight laboratory-reared Atlantic salmon parr $(10 \mathrm{~g})$ with no known prior exposure to rickettsia were intraperitoneally (IP) injected with $0.1 \mathrm{ml}$ of the macerate and maintained in aerated, fresh water at $10 \pm 1^{\circ} \mathrm{C}$. Liver from the same naturally infected salmon, also shown to contain RLO, was stored at $-20^{\circ} \mathrm{C}$ for $36 \mathrm{~d}$, after which a portion was thawed, macerated in saline and injected into 20 naive parr $(10 \mathrm{~g})$ as above. Spleen imprints prepared from experimentally infected mortalities were fixed in 100\% methanol and stained with either Giemsa or a fluorescein isothiocyanate-(FITC) conjugated antibody (IFAT, see below). Kidney from the mortalities was aseptically streaked onto brain heart infusion agar (BHIA) and incubated at $18^{\circ} \mathrm{C}$.

Cell culture of RLO. Monolayer cultures of chinook salmon embryo cells [CHSE-214; American Type Culture Collection (ATCC), CRL 1681; Lannan et al. 1984] in minimal essential medium, supplemented with $10 \%$ heat-inactivated fetal bovine serum (FBS) and $2.5 \mu \mathrm{g}$ $\mathrm{ml}^{-1}$ Fungizone (amphotericin $\mathrm{B}_{i}$ Gibco), were maintained at $15 \pm 1^{\circ} \mathrm{C}$ in 25 or $75 \mathrm{~cm}^{2}$ polystyrene flasks or in 6 -well tissue culture plates. Except where indicated other antibiotics were omitted from the medium. Fifteen days following injection with naturally infected kidney, 2 salmon were killed using benzocaine and thoroughly rinsed with $70 \%$ ethanol. The fish were aseptically bisected anterior to the dorsal fin, and kidney tissue was transferred into CHSE cultures in 6 well plates using a sterile loop. Cultures were monitored using an inverted microscope, and thin smears were prepared from supernatants at intervals following the detection of cytopathic effect (CPE). Smears were fixed in 100\% methanol and stained with Giemsa or for IFAT (see below). Supernatant from a culture with complete CPE was passed through a $0.2 \mu \mathrm{m}$ filter and inoculated onto uninfected CHSE cells. A sample of the unfiltered supernatant was inoculated onto blood agar and maintained at $15^{\circ} \mathrm{C}$. Cultures of the RLO (designated ECR0811) were maintained by serial passage in CHSE cells and aliquots were supplemented with $10 \%$ dimethyl sulphoxide and 10\% FBS and stored in liquid nitrogen.

Separate groups of about 20 laboratory-reared rainbow trout Oncorhynchus mykiss (25 g), coho salmon Oncorhynchus kisutch (10 g), Atlantic salmon (10 g) and common carp Cyprinus carpio $(5 \mathrm{~g})$ were acclimated for $1 \mathrm{wk}$ at $18.0 \pm 0.5^{\circ} \mathrm{C}$ in aerated, flowing well water (one tank per group). Following acclimation, each fish was IP injected with $0.1 \mathrm{ml}$ of $10^{-1}$ diluted infected culture supernatant. Levels of viable RLO in supernatants were estimated by calculating the dilution required to infect $50 \%$ of cultures $\left(\mathrm{TCID}_{50}\right)$. Uninjected control fish were maintained under similar conditions. Numbers of mortalities were recorded and spleen imprints from mortalities were examined using IFAT. Kidney tissue was streaked onto BHIA and incubated at $18^{\circ} \mathrm{C}$. 
The sensitivity of cultured ECR0811 to oxolinic acid, flumequine, oxytetracycline, chloramphenicol and gentamicin was examined by calculating minimal inhibitory concentrations (MIC) for each in 96-well plates by using methods described by Smith et al. (1996b). CHSE cultures in a 96 -well plate were inoculated with approximately $10^{2.5} \mathrm{TCID}_{50}$ well $^{-1}$ of cultured RLO and incubated for $10 \mathrm{~d}$ at $15^{\circ} \mathrm{C}$. The MIC for each antibiotic was defined as the highest dilution in which no CPE was detected.

Three additional strains of Piscirickettsia salmonis [LF-89', ATCC No. V(R)1361; CR288 and CR1010, Marine Harvest Chile] were maintained in CHSE cells as described above.

Preparation of antibodies against Piscirickettsia salmonis (strain LF-89). Supernatant pooled from $150 \mathrm{~cm}^{2}$ flasks containing infected CHSE cultures was centrifuged at $500 \times g$ for $15 \mathrm{~min}$. Bacteria in the supernatant were washed 3 times in sterile saline by centrifugation at $13000 \times g$ for $15 \mathrm{~min}$ and were resuspended in $0.5 \%$ formalin-saline. Any remaining debris was allowed to sediment overnight at $4^{\circ} \mathrm{C}$. Protein content in the resulting supernatant was estimated using the $B C A$ assay (Pierce).

Two naive, female New Zealand white rabbits were intramuscularly injected with the LF-89 antigen emulsified with an equal volume of Freund's incomplete adjuvant (FIA). Thereafter, rabbits received subcutaneous injections of antigen at regular intervals. Immunoglobulin was purified from the resulting serum by precipitation in $50 \%$ saturated $\left(\mathrm{NH}_{4}\right)_{2} \mathrm{SO}_{4}$ and anion exchange chromatography. Another rabbit-antiPiscirickettsia salmonis (strain LF-89) serum was obtained from Dr. J. L. Fryer, Oregon State University (Lannan et al. 1991).

Female balb/c mice were intraperitoneally (IP) injected with the LF-89 antigen emulsified with a synthetic adjuvant (Ribi, Sigma). Mice were boosted 22 and 55 d later by IP injection of antigen. Sera obtained on Days 35 and 75 were screened by enzyme-linked immunosorbent assay (ELISA; see below). On Day 76, a mouse received an IP injection of antigen, and $4 \mathrm{~d}$ later spleen cells were isolated and fused with SP-2 myeloma cells and cloned by limiting dilution. Positive hybridoma clones were chosen by the unique reaction of their supernatants with Piscirickettsia salmonis in an ELISA. Briefly, enzyme immunoassay (EIA) plates were incubated overnight with $2 \mu \mathrm{g}$ well ${ }^{-1}$ LF-89 or uninfected CHSE antigen, blocked with BSA and incubated with undiluted hybridoma supernatant or polyclonal serum. Plates were then incubated with an antiglobulin-horseradish peroxidase conjugate (Cappel, ICN), and colour development followed incubation with 2,2'-azino-bis(3-ethylbenz-thiazoline-6-sulphonic acid) (Sigma). Positive clones were subcloned and stored in liquid nitrogen. The immunoglobulin isotype secreted by each positive clone was determined by double diffusion immunoprecipitation. Hybridoma supernatants were stored at $-20^{\circ} \mathrm{C}$ or $1.0 \mathrm{ml}$ aliquots were lyophilised

The specificity of 1 monoclonal antibody (2C3) was assessed by monitoring lysed LF-89 following fractionation on a gel filtration column for 2-keto-3deoxyoctonate (KDO) and for reactivity with the MAb. Briefly, LF-89 antigen was digested with $0.25 \%$ proteinase $\mathrm{K}$ ( $\mathrm{PK}_{i}$ Sigma) for 60 min at $37^{\circ} \mathrm{C}$, followed by boiling for $10 \mathrm{~min}$ in lysis buffer $[10 \mathrm{mM}$ Tris, $10 \mathrm{mM}$ ethylenediamine tetra-acetic acid (EDTA), $0.1 \%$ sodium dodecyl sulphate (SDS), $0.1 \%$ sodium deoxycholate, $\mathrm{pH}$ 7.2]. The lysate was desalted in $\mathrm{dH}_{2} \mathrm{O}$ using a Sephadex G75 column (Pharmacia), and fractionated in $20 \mathrm{mM}$ Tris ( $\mathrm{pH} 7.7$ ) using a Sephacryl S300 column (Pharmacia). Eluted fractions were assayed for KDO using the thiobarbituric acid assay (Osborn 1963) and compared with an Escherichia coli (O55:B5) lipopolysaccharide (LPS; Difco) standard. Fractions eluted from the column were also monitored for immunoreactivity with MAb using the ELISA.

Indirect fluorescent antibody test (IFAT). Methanolfixed smears of culture supernatants or tissue imprints were post-fixed in acetone. Samples were then incubated for 30 min with rabbit sera or with MAb, washed for 15 min with phosphate buffered saline (PBS; $\mathrm{pH} 7.2$ ) and incubated for an additional $30 \mathrm{~min}$ in the dark with a diluted fluorescein isothiocyanate-conjugated antiglobulin (Cappel, ICN) to which Evan's blue was added as a counterstain. Following washing with PBS. samples were coverslipped with FA mounting fluid (Difco) and examined using an epifluorescent compound microscope.

Electrophoresis and immunoblotting. Antigen was prepared from cultures of all strains and from uninfected CHSE cells as described above but without formalin fixation. Washed cells were resuspended in electrophoresis sample buffer containing SDS and 2 mercaptoethanol and boiled for $5 \mathrm{~min}$. Prior to boiling, some samples of all strains were first incubated with $0.25 \%$ PK. Similarly, some samples of PK-treated strain LF-89 were incubated with $1.0 \%$ periodic acid $\left(37^{\circ} \mathrm{C}\right.$, $60 \mathrm{~min}$ ) prior to boiling. Samples were resolved in $12 \%$ polyacrylamide gels (Laemmli 1970) and either stained with silver nitrate for LPS (Tsai \& Frasch 1982) or electrophoretically blotted to nitrocellulose (NC) membranes (Towbin et al. 1979), blocked with 3\% skim milk and probed with purified rabbit serum or with $\mathrm{MAb} 2 \mathrm{C} 3$ and then with a horseradish peroxidaseconjugated antiglobulin (Cappel, ICN). Immunoreactive bands were visualized following incubation of $\mathrm{NC}$ with 4-chloro-1-naphthol (Diagnostic Chemicals Ltd) and $\mathrm{H}_{2} \mathrm{O}_{2}$. 


\section{RESULTS}

Atlantic salmon parr showed abdominal distension, darkening of the skin, lethargy and gill pallor by $14 \mathrm{~d}$ following IP injection with fresh, naturally infected kidney homogenate. Two moribund fish were killed 15 days post infection (DPI) for isolation of the RLO into culture. Mortalities were first observed 19 DPI, and 4 of 6 remaining fish died by 24 DPI. No further mortalities were observed during the succeeding $43 \mathrm{~d}$. In contrast, no fish died during the 35 d following injection with a homogenate prepared from infected salmon liver that had been stored at $-20^{\circ} \mathrm{C}$. RLO had previously been identified histologically and by IFAT in the naturally infected kidney and liver used to prepare the inocula (Cusack et al. 1997). Giemsa-stained spleen imprints prepared from mortalities contained numerous small, round to pleomorphic and basophilic cocco-bacilli. Morphologically similar structures fluoresced following incubation with rabbit anti-LF-89 sera or MAb $2 \mathrm{C} 3$. Fluorescence was not detected when preimmune sera or an irrelevant serum (rabbit-anti-Aeromonas salmonicida) was used. There was no evidence of RLO in uninjected salmon and no other bacterial pathogens were cultured using BHIA.

Cytopathic effect (CPE) was first observed in CHSE cultures $4 \mathrm{~d}$ following inoculation with the experimentally infected salmon kidney. CPE was typified by scattered clusters of swollen cells that eventually coalesced into areas within the monolayer that were devoid of cells and surrounded by a rim of swollen cells. Complete CPE occurred between 10 and $12 \mathrm{~d}$ following infection of cultures. CPE was not evident in CHSE cultures during a 28 d observation period following inoculation with infected supernatant that had been passed through a $0.22 \mu \mathrm{m}$ filter nor was growth evident on blood agar for $21 \mathrm{~d}$ following inoculation with fresh culture supernatant. No CPE was observed in cultures inoculated with tissue from fish injected with the frozen liver homogenate.

Giemsa-stained culture supernatants of LF-89, CR288, CR1010 and ECR0811 contained small, round or pleomorphic, basophilic cocco-bacilli that occurred freely or within CHSE cells and were not detected in stained smears of uninfected cultures. These structures fluoresced following incubation with rabbit antisera or with MAb 2C3. Fluorescent structures were not seen in normal CHSE cultures.

Supernatant from 12 d cultures of ECR0811 (second passage) contained $1.0^{4.875} \mathrm{TCID}_{50} \mathrm{ml}^{-1}$ of viable RLO. The virulence of this strain differed among test species such that injection with $10^{2.875}$ TCID $_{50}$ killed $100 \%$ of Atlantic salmon, $62 \%$ of coho salmon and $22.5 \%$ of rainbow trout. In contrast, no carp died during the $21 \mathrm{~d}$ observation period following injection (Fig. 1). Small,

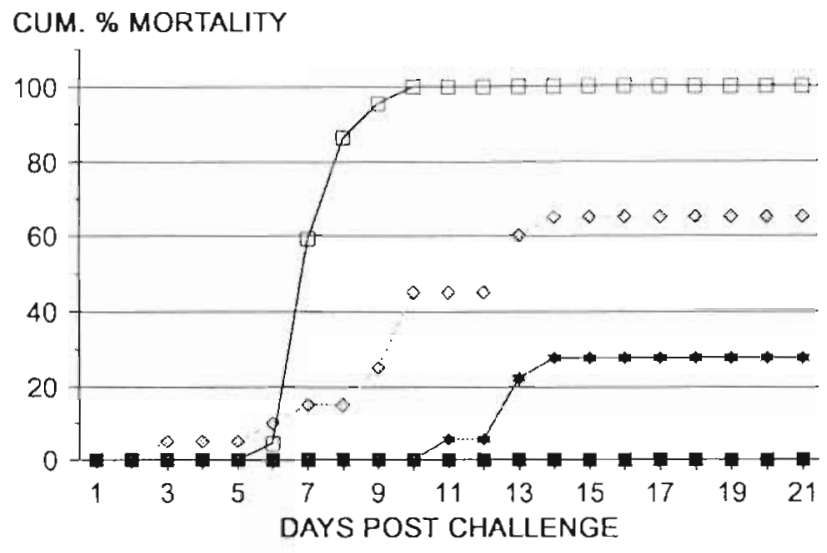

Fig. 1 Cumulative percent mortality among salmonid and non-salmonid species tollowing intraperitoneal injection with $10^{2.875} \mathrm{TCID}_{50}$ of cultured salmonid Rickettsiales-likeorganism, strain ECR0811. Salmo salar (प), n $=22$; Oncorhynchus kisutch $(0), \mathrm{n}=20$; Oncorhynchus mykiss (*), $\mathrm{n}=20 ;$ Cyprinus carpio (a), $\mathrm{n}=22$

round to pleomorphic fluorescent cocco-bacilli were detected in IFAT examinations of spleen imprints prepared from mortalities. Na control fish died during the same period and no bacterial pathogens could be cultured from mortalities onto BHIA.

Cultured ECR0811 were sensitive to chlorampheni$\mathrm{col}\left(\mathrm{MIC}=0.4 \mu \mathrm{g} \mathrm{ml}^{-1}\right)$, axytetracycline $(\mathrm{MIC}=1.6 \mu \mathrm{g}$ $\left.\mathrm{ml}^{-1}\right)$, oxolinic acid ( $\mathrm{MIC}=3.2 \mu \mathrm{g} \mathrm{ml}^{-1}$ ) and flumequine $\left(\mathrm{MIC}=3.2 \mu \mathrm{g} \mathrm{ml}^{-1}\right)$ and were insensitive to gentamicin $\left(\mathrm{MIC}=51.2 \mu \mathrm{g} \mathrm{m}^{-1}\right.$ )

All 4 RLO strains examined were electrophoretically similar to one another. An intense silver-staining band that migrated slightly above the dye front $(\sim 12 \mathrm{kDa})$ was evident in PK digested samples of all 4 RLO strains. A faint and diffuse band of approximately $15 \mathrm{kDa}$ was evident in LF-89 and CR1010 but not in CR288 or ECR0811. No other bands were evident in silver-stained gels of PK-digested samples from any strain

Similar profiles of immunoreactive bands were observed in 2 Chilean strains of salmonid RLO (LF-89, CR1010) and in the Canadian salmonid RLO (ECR0811) following incubation with rabbit-anti-Piscirickettsia salmonis serum (Fig. 2, lanes 2 to 4). Although several of these bands were absent following PK treatment, numerous immunoreactive bands, extending from less than $20 \mathrm{kDa}$ to greater than $95 \mathrm{kDa}$ in all 4 RLO strains, evidently resisted PK digestion (Fig. 2, lanes 5 to 8). Comparisons of the immunoblots indicated that PK-sensitive bands of approximately 125 , $98,93,89,65,60,55,45$ and $32 \mathrm{kDa}$ were shared among strains LF-89, CR1010 and ECR0811 Immunoreactivity of all but the $\sim 12 \mathrm{kDa}$ PK-resistant band was abolished by treatment with periodic acid (Fig. 2, lanes 
Fig. 2. Immunoblots of antigen from salmonid Rickettsiales-like organisms (resolved in $12 \%$ polyacrylamide gels) probed with rabbit anti-LF-89 serum A. Lanes 1 to $4\left(7.5 \mu \mathrm{g}\right.$ lane $\left.\mathrm{e}^{-1}\right)$ : undigested antigen. (1) Uninfected CHSE cell antigen, (2) LF-89, (3) CR1010, (4) ECR0811 Lanes 5 to $8(7.5 \mu \mathrm{g}$ lane $\left.{ }^{-1}\right)$ : antigen digested with Proteinase K. (5) LF-89, (6) CR288, (7) CR1010, (8) ECR0811. Lanes 9 and $10\left(10 \mu \mathrm{glane}^{-1}\right)$ : LF-89 antigen digested with proteinase $\mathrm{K}$. (9) Without periodic acid, (10) $1 \%$ periodic acid. Molecular markers are shown in $\mathrm{kDa}$

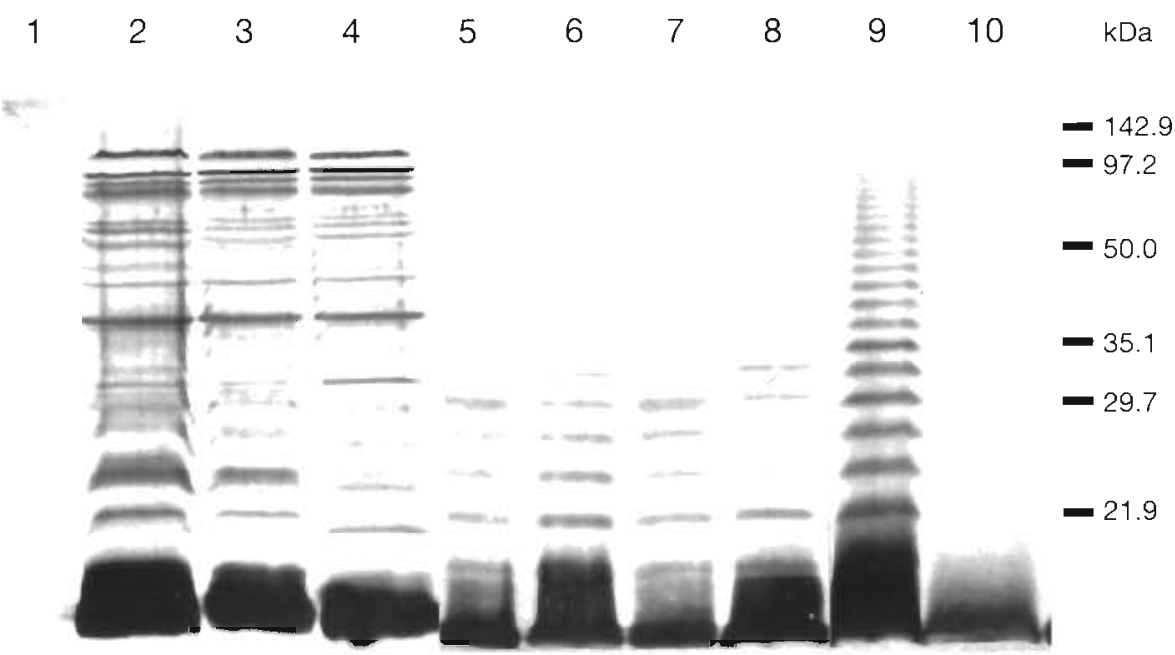

$9 \& 10)$. A few poorly immunoreactive bands were observed in normal CHSE cell antigen (Fig. 2, lane 1).

Monoclonal antibody $2 \mathrm{C} 3$ reacted with an epitope that occurred in strains LF89, CR288, CR1010 and ECR0811. This epitope evidently resided on antigens possessing a wide range of molecular masses, resulting in a ladder pattern extending from less than $20 \mathrm{kDa}$ to greater than $95 \mathrm{kDa}$. Similar immunoblot profiles were observed in PK-treated samples (Fig. 3, lanes 3 to 6). Treatment of LF-89 antigen with periodic acid abolished immunoreactivity with $\mathrm{MAb} 2 \mathrm{C} 3$ (Fig. 3, lanes 1

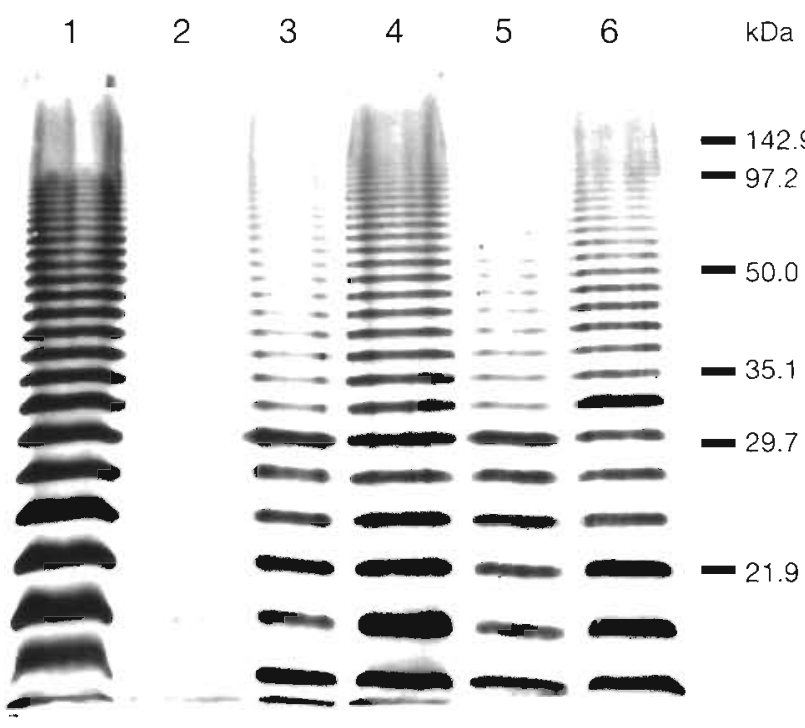

Fig. 3. Immunoblots of proteinase K-treated antigen from salmonid Rickettsiales-like organisms (RLO) (resolved in 12\% polyacrylamide gels) probed with monoclonal antibody $2 \mathrm{C} 3$. Lanes 1 and 2: (10 $\mathrm{kg}$ lane ${ }^{-1}$ ), strain LF-89. (1) Without periodic acid, (2) $1 \%$ periodic acid. Lanes 3 to $6\left(7.5 \mu \mathrm{g} \operatorname{lane}^{-1}\right)$ : RLO strains without periodic acid. (3) LF-89, (4) CR288, (5) CR1010,

(6) ECR0811. Molecular weight markers are shown in $\mathrm{kDa}$
\& 2). KDO was detected in samples of cultured strain LF-89. Fractionation of the LF-89 lysate on Sephacryl S300 resulted in a large peak that eluted with the void volume [partition coefficient $\left(K_{d v}=0\right)$ ] and a second, smaller peak $\left(K_{a v}=0.96\right)$. MAb reactivity and the KDO eluted exclusively with the first peak.

\section{DISCUSSION}

Clinical signs similar to those described during natural infection (Cusack et al. 1997) were reproduced in naive salmon parr by intraperitoneal injection with a homogenate prepared from fresh, naturally infected kidney. An RLO (strain ECR0811) isolated from the experimentally infected salmon multiplied and produced a characteristic CPE in CHSE cells that was similar to that produced by salmonid RLO from British Columbia, Scotland and Norway (Brocklebank et al. 1992, Olsen et al. 1993, Grant et al. 1996) and by Piscirickettsia salmonis (Garcés et al. 1991). Cultured ECR0811 was most virulent in Atlantic salmon and less so in other salmonid and non-salmonid species. The differential virulence displayed by cultures of this RLO among fish species was similar to that of $P$. salmonis, which is also more virulent in Atlantic and coho salmon than it is in rainbow trout (Cvitanich et al. 1991, Garcés et al. 1991, Smith et al. 1996a). Failure of ECR0811 to cause mortality in carp was similar to observations of Trevors et al. (1996) in which carp and goldfish Carassius auratus were resistant to experimental infection with a cultured Chilean strain of $P$. salmonis. In another study, Chern \& Chao (1994) concluded that a cichlid-derived RLO had a narrow host range. It has been suggested that host specificity among salmonid RLOs may also be reflected in the inability of the cultured organisms to infect cell lines derived from non- 
salmonid fishes (Almendras et al. 1997b). Whether the specificity of teleost RLOs is a function of host-cell recognition or of host response to infection is the focus of ongoing studies.

Strain ECR0811 was shown to be sensitive to antibiotics typically utilized in salmonid aquaculture. The pattern of antibiotic sensitivity displayed by ECR0811 was similar to that of Piscirickettsia salmonis (CVitanich et al. 1991) and to an RLO isolated from Atlantic salmon in Scotland (Grant et al. 1996). New observations suggest that recently isolated Chilean strains of $P$. salmonis have developed resistance to certain antibiotics (Smith et al. 1996b). Since gentamicin is not used in Canadian salmon culture, the apparent resistance of ECR0811 to gentamicin described here is more likely to be due to the relative impermeability of some eukaryotic cells to this aminoglycoside, resulting in lower intracellular concentrations (Fountain et al. 1985), than to acquired antibiotic resistance of ECR0811.

Antigenic homogeneity was observed among the 4 geographically diverse RLO strains examined here. These strains shared as many as 9 antigenically similar proteins ranging from 32 to $125 \mathrm{kDa}$. Polyclonal serum and a MAb also recognized several non-protein antigens in all strains: a low molecular weight band (only recognized by the rabbit serum) and multiple bands of higher molecular weight that, upon SDS-PAGE, resolved in a ladder pattern reminiscent of LPS O-antigen. The identity of the MAb-reactive epitope as a constituent of LPS was strongly suggested by its resistance to proteinase $\mathrm{K}$ degradation as well as, following gel filtration chromatography of an LF-89 lysate, the coelution of KDO with maximum MAb activity. This is the first time $\mathrm{KDO}$ has been identified in a strain of Piscirickettsia salmonis, and further work is necessary to document the occurrence of this molecule in strains other than LF-89. In a recent study, rabbit antiserum recognized 6 antigens in $P$. salmonis (strain LF-89) (Kuzyk et al. 1996). Antigens of apparent molecular masses of $51,55,60$ and $65 \mathrm{kDa}$, similar to some of those described here, were proteinaceous, whereas antigens of 16 and $\sim 11 \mathrm{kDa}$ were low molecular weight components of a lipooligosaccharide. Failure of conventional silver stains to completely visualize the LPS of the salmonid RLO strains examined in either Kuzyk et al. (1996) or the present study was probably because of unusual O-polysaccharide sugar residues, as in Rickettsia siberica LPS, which also stained poorly with silver (Amano et al. 1993).

This study has established that the RLO recently isolated in eastern Canada is a primary pathogen in salmonid fish. Pure cultures isolated from experimentally infected fish were virulent in salmonids, and RLOs were re-isolated from moribund animals into cell culture. Failure to detect evidence of infection with other known bacterial or viral pathogens either in salmon or in cell culture further supported this conclusion. Other studies have implicated RLOs as primary pathogens in farmed salmon and tilapia (Cvitanich et al. 1991, Chern \& Chao 1994, Grant et al. 1996). Indeed, until the initial description of this RLO (Cusack et al. 1997), eastern North America was the only major salmon producing region from which a salmonid RLO had not been identified. The similarities in cultural, virulence and antigenic characteristics of the Canadian isolate to those of Piscirickettsia salmonis suggest a strong identity between these organisms. This may provide support for the suggestion of Cusack et al. (1997) that the outbreak from which ECR0811 was isolated may have originated in untreated effluent from a local plant that has processed fish from other geographic regions. Assuming the liver from naturally infected salmon initially to have a viable RLO intensity similar to that of kidney, our inability to infect salmon with the liver that had been stored at $-20^{\circ} \mathrm{C}$ suggested that freezing may reduce the risk of dissemination of viable RLOs during global transfer of fish for processing. Regardless of the origin of RLO strain ECR0811, the present results indicate it belongs to $P$. salmonis. The relationship of $P$. salmonis to serologically distinct RLOs isolated from salmon in Scotland and Chile (Cvitanich et al. 1995. Grant et al. 1996) and to pathogenic RLOs from non-salmonid species (Chern \& Chao 1994) requires careful examination. Thus, until reservoir species and modes of transmission of salmonid RLOs are better understood, these organisms, given their evident ubiquitous distribution and potential to cause mortality, will continue to pose a significant risk to salmon farming in all regions.

Acknowledgements. The authors thank Dr Enrique Madrid, recently of Marine Harvest Chile, for his contribution of cultured Piscirickettsia salmonis. We also acknowledge Mr Sean LeBlanc for maintaining fish, Ms Shelly Ebert for photographic services and Ms Judy Sheppard for hybridoma production.

\section{LITERATURE CITED}

Alday-Sanz V, Rodger H, Turnbull T, Adams A, Richards RH (1994) An immunochemical diagnostic test for rickettsial disease. J Fish Dis 17:189-191

Almendras FE, Fuentealba IC, Jones SRM, Markham F, Spangler $E$ (1997a) Experimental infection and horizontal transmission of Piscirickettsia salmonis in freshwater raised Atlantic salmon, Salmo salar. J Fish Dis 20:409-418

Almendras FE, Jones SRM, Fuenteal.ba C, Wright GM (1997b) In vitro infection of a cell line from rctalurus nebulosus with Piscirickettsia salmonis. Can J Vet Res 61:66-68

Amano KI, Fujita M, Suto T (1.993) Chemical properties of lipopolysaccharides from spotted fever group rickettsiae 
and their common antigenicity with lipopolysaccharides from Proteus species. Infect Immun 61:4350-4355

Brocklebank JR, Speare DJ, Armstrong RD, Evelyn T (1992] Septicemia suspected to be caused by a rickettsia-like agent in farmed Atlantic salmon. Can Vet J 33:147-156

Chern RS, Chao CB (1994) Outbreaks of a disease caused by a rickettsia-like organism in cultured tilapias in Taiwan Fish Pathol 29:61-71

Cusack R, Groman D, Jones S (1997) The first reported rickettsial infections of Atlantic salmon in eastern North America. In: VII In International Conference 'Diseases of Fish and Shellfish', Abstract Book. Eur Assoc Fish Pathol, Edinburgh, p 0-109

Cvitanich JD, Garate NO, Silva PC, Andrade VM, Figueroa PC, Smith CE (1995) Isolation of a new rickettsia-like organism from Atlantic salmon in Chile. American Fisheries Society, Fish Health Section, Newsletter 23:1-3

Cvitanich JD, Garate NO, Smith CE (1991) The isolation of a rickettsia-like organism causing disease and mortality in Chilean salmonids and its confirmation by Koch's postulates. J Fish Dis 14:121-145

Evelyn TPT, Kent ML (1992) Salmonid rickettsial septicemia. In: Kent ML (ed) Diseases of saltwater netpen-reared salmonid fishes in the Pacific northwest. Can J Fish Aquat Sci Spec Publ 116:18-19

Fountain $M W$, Weiss SJ, Fountain AG, Shen A, Lenk RP (1985) Treatment of Brucella canis and Brucella abortus in vitro and in vivo by stable plurilamellar vesicleencapsulated aminoglycosides. J Infect Dis 152:529-535

Fryer JL, Lannan CN (1994) Rickettsial and chlamydial infections of freshwater and marine fishes, bivalves, and crustaceans. Zool Stud 33:95-107

Fryer JL, Lannan CN, Garcés LH, Larenas JJ, Smith PA (1990) Isolation of a rickettsiales-like organism from diseased coho salmon (Oncorhynchus kisutch) in Chile. Fish Pathol 25:107-114

Fryer JL, Lannan CN, Giovannoni SJ, Wood ND (1992) Piscirickettsia salmonis gen. nov., sp. nov., the causative agent of an epizootic disease in salmonid fishes. Int $\mathbf{J}$ Syst Bacteriol 42:120-126

Garcés LH, Larenas JJ, Smith PA, Sandino S, Lannan CN, Fryer JL (1991) Infectivity of a rickettsia isolated from coho salmon Oncorhynchus kisutch. Dis Aquat Org 11:93-97

Grant AN, Brown AG, Cox DI, Birkbeck TH, Griffen AA (1996) Rickettsia-like organism in farmed salmon. Vet Rec 138:423

Editorial responsibility: David Bruno,

Aberdeen, Scotland, UK
Kuzyk MA, Thornton JC, Kay WW (1996) Antigenic characterization of the salmonid pathogen Piscirickettsia salmonis. Infect Immun 64:5205-5210

Laemmli UK (1970) Cleavage of structural proteins during the assembly of the head of bacteriophage T4. Nature (London) 227:154-159

Lannan CN, Ewing SA, Fryer JL (1991) A fluorescent antibody test for the detection of the rickettsia causing disease in Chilean salmonids. J Aquat Anim Health 3:229-234

Lannan CN, Winton JR, Fryer JL (1984) Fish cell lines: establishment and characterization of nine cell lines from salmonids. In Vitro 20:671-676

Mauel MJ (1996) Evidence for molecular diversity of Piscirickettsia salmonis. PhD dissertation, Oregon State University, Corvallis

Olsen AB, Evensen O, Speilberg L, Melby HP, Håstein I (1993) ' $N y^{\prime}$ laksesykdom forårsaket av rickettsie. Norsk Fiskeoppdrett 12:40-41

Osborn MJ (1963) Studies on the gram-negative cell wall. I Evidence for the role of 2-keto-3-deoxyoctonate in the lipopolysaccharide of Salmonella typhimurium. Proc Natl Acad Sci USA 50:499-506

Rodger HD, Drinnan EM (1993) Observation of a rickettsialike organism in Atlantic salmon, Salmo salar L., in Ireland. J Fish Dis 16:361-369

Smith PA, Contreras JR, Garcés LH, Larenas JJ, Oyanedel S, Caswell-Reno P, Fryer JL (1996a) Experimental challenge of coho salmon and rainbow trout with Piscirickettsia salmonis. J Aquat Anim Health 8:130-134

Smith PA, Vecchiola IM, Oyanedel S, Garcés LH, Larenas J, Contreras J (1996b) Antimicrobial sensitivity of four isolates of Piscirickettsia salmonis. Bull Eur Assoc Fish Pathol 16:164-168

Towbin 11, Staehelin T, Bordon J (1979) Electrophoretic transfer of protein from polyacrylamide gels to nitrocellulose sheets, procedure and some applications. Proc Natl Acad Sci USA 76:4350-4354

Trevors CM, Jones SRM, Markham RJF (1996) Superoxide anion production in Piscirickettsia salmonis infected macrophages isolated from Cyprinus carpio and Salmo salar. In Gudding R, Lillehaug A, Midtlyng PJ, Brown F (eds) Fish vaccinology, Vol 90. Dev Biol Stand, Karger, Basel, p 66

Tsai CM, Frasch CE (1982) A sensitive silver stain for detecting lipopolysaccharide in polyacrylamide gels. Anal Biochem 119:1.15-11.9

Submitted: August 4, 1997; Accepted: January 28, 1998

Proofs received from author(s): March 26, 1998 